\title{
Numerical Modeling of the Influence of Solar Activity on the Global Circulation in the Earth's Mesosphere and Lower Thermosphere
}

\author{
Igor Mingalev and Victor Mingalev \\ Kola Scientific Center of the Russian Academy of Sciences, Polar Geophysical Institute, Fersman Street 14, Apatity 184209, Russia \\ Correspondence should be addressed to Victor Mingalev, mingalev@pgia.ru
}

Received 4 November 2011; Revised 12 January 2012; Accepted 25 January 2012

Academic Editor: M. V. Klimenko

Copyright ( $) 2012$ I. Mingalev and V. Mingalev. This is an open access article distributed under the Creative Commons Attribution License, which permits unrestricted use, distribution, and reproduction in any medium, provided the original work is properly cited.

\begin{abstract}
The nonhydrostatic model of the global neutral wind system of the earth's atmosphere, developed earlier in the Polar Geophysical Institute, is utilized to investigate how solar activity affects the formation of the large-scale global circulation of the mesosphere and lower thermosphere. The peculiarity of the utilized model consists in that the internal energy equation for the neutral gas is not solved in the model calculations. Instead, the global temperature field is assumed to be a given distribution, that is, the input parameter of the model. Moreover, in the model calculations, not only the horizontal components but also the vertical component of the neutral wind velocity is obtained by means of a numerical solution of a generalized Navier-Stokes equation for compressible gas, so the hydrostatic equation is not applied. The simulation results indicate that solar activity ought to influence considerably on the formation of global neutral wind system in the mesosphere and lower thermosphere. The influence is conditioned by the vertical transport of air from the lower thermosphere to the mesosphere and stratosphere. This transport may be rather different under distinct solar activity conditions.
\end{abstract}

\section{Introduction}

During the last three decades, several general circulation models of the lower and middle atmosphere have been developed (e.g., see [1-11]). It can be noticed that the existing general circulation models of the lower and middle atmosphere may be successfully utilized for simulation of the slow climate changes. Unfortunately, these models cannot produce the vertical atmospheric wind with an acceptable accuracy. The fact is that the momentum equation for the vertical velocity is omitted in commonly used general circulation models, and the vertical velocity is obtained with the help of simple hydrostatic equation. Unfortunately, these models can not produce the vertical atmospheric wind with an acceptable accuracy. As a consequence of the simplification, such models do not provide an ability to simulate the largescale global circulation in all regimes, in particular, under disturbed conditions. As is well known, the global models just mentioned produce the vertical component of the wind velocity having the values of several centimeters per second at levels of the lower thermosphere. While the observed vertical velocity is known to achieve up to some tens $\mathrm{m} / \mathrm{s}$ at levels of the mesosphere and lower thermosphere in high-latitude regions (see [12-16]). Thus, it is necessary to use more complex general circulation models, describing the vertical transport more adequately, for simulation the transient large-scale global circulation of the middle atmosphere and lower thermosphere.

In the Polar Geophysical Institute (PGI), the nonhydrostatic model of the global neutral wind system in the earth's atmosphere has been developed not long ago $[17,18]$. This model enables to calculate three-dimensional global distributions of the zonal, meridional, and vertical components of the neutral wind at levels of the troposphere, stratosphere, mesosphere, and lower thermosphere, with whatever restrictions on the vertical transport of the neutral gas being absent. This model has been utilized in order to simulate the global circulation of the middle atmosphere for conditions 


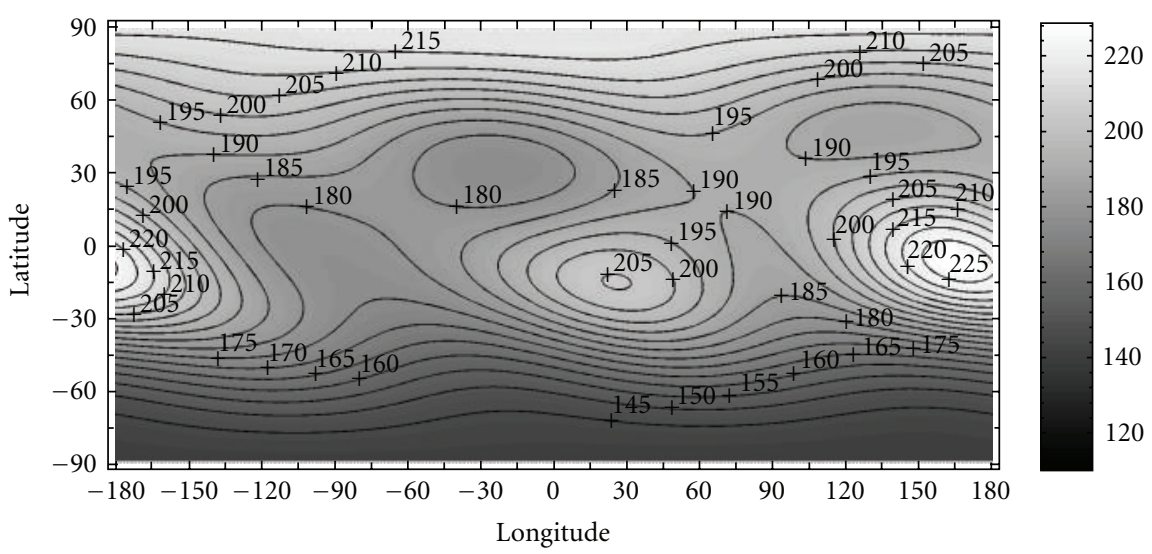

(a)

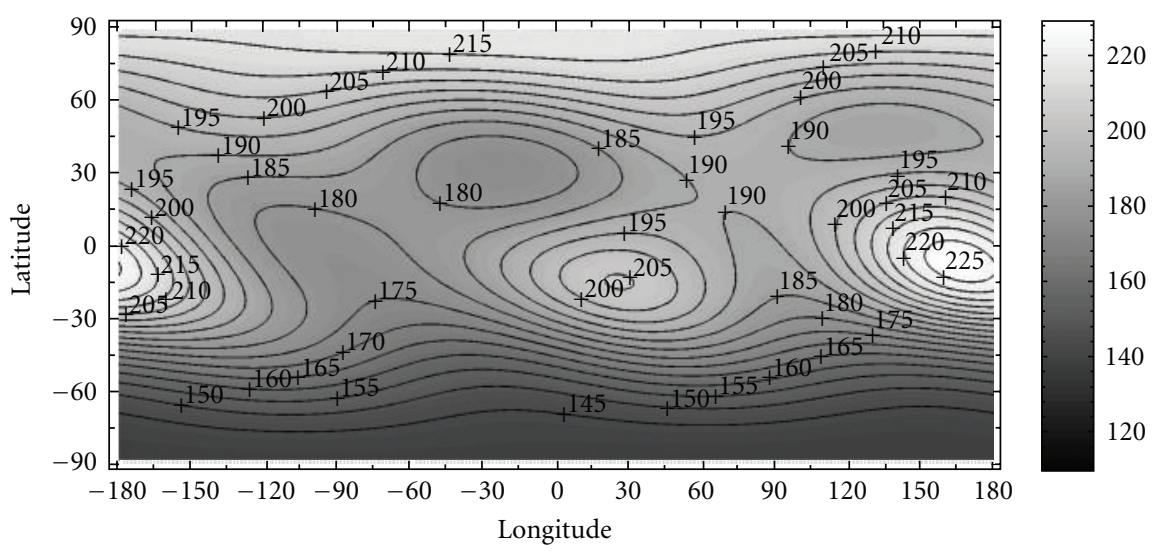

(b)

FIgURE 1: The global distributions of the atmospheric temperature $(\mathrm{K})$ at $90 \mathrm{~km}$ altitude, obtained from the NRLMSISE-00 empirical model for 16 January, $U T=10.30$ and calculated for two distinct values of solar activity: $F_{10.7}=101$ (a) and $F_{10.7}=230$ (b).

corresponding to summer and winter in the northern hemisphere (see [17-19]). It has been found in these studies that the global distributions of the neutral wind, calculated for summer and winter periods in the northern hemisphere, in particular, the large-scale circumpolar vortices, are consistent with the planetary circulations of the atmosphere, obtained from observations.

The purpose of the present work is to continue these studies and to investigate numerically, using the nonhydrostatic model of the global neutral wind system $[17,18]$, how solar activity affects the formation of the large-scale global circulation of the mesosphere and lower thermosphere.

\section{Mathematical Model}

The nonhydrostatic model of the global neutral wind system in the earth's atmosphere, developed earlier in the PGI $[17,18]$ is utilized in the present study. The utilized model produces three-dimensional global distributions of the zonal, meridional, and vertical components of the neutral wind velocity and neutral gas density at the levels of the troposphere, stratosphere, mesosphere, and lower thermosphere. The characteristic feature of the model is that the vertical component of the neutral wind velocity, as well as horizontal components of the neutral wind, is obtained by means of a numerical solution of the appropriate momentum equation for a viscous gas without any simplifications of this equation, with the hydrostatic equation being not used. Moreover, the model does not include the internal energy equation for the neutral gas. Instead, the global temperature field is assumed to be a given distribution. It is known that the atmospheric temperature distributions, calculated by using the existing global circulation models containing the internal energy equation, as a rule, differ from observed distributions of the atmospheric temperature. These differences are conditioned by uncertainty and complexity in various chemicalradiational heating and cooling rates. Therefore, there is no reason to expect an exact correspondence between the calculated and measured temperatures of the neutral gas. On the other hand, over the last years empirical models of the global atmospheric temperature field have been successfully developed which have a satisfactory accuracy. In the present study, we take the global temperature distribution from the NRLMSISE-00 empirical model [20] and consider it to be an input parameter of the utilized model.

However, the utilized model is not able to simulate the gravity waves origin and propagation because of the time independence of the temperature in the model calculations. 


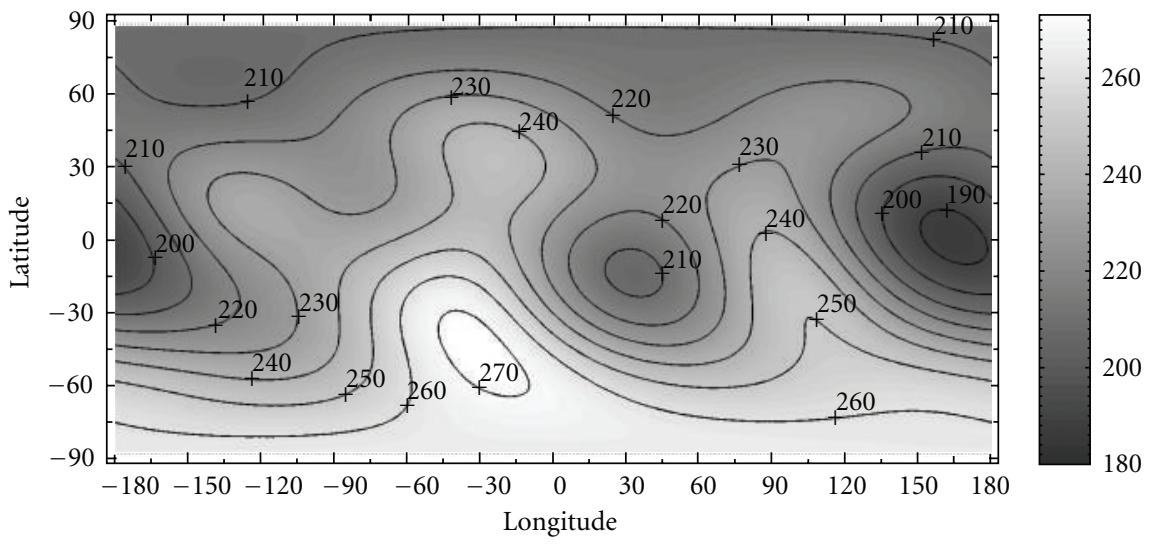

(a)

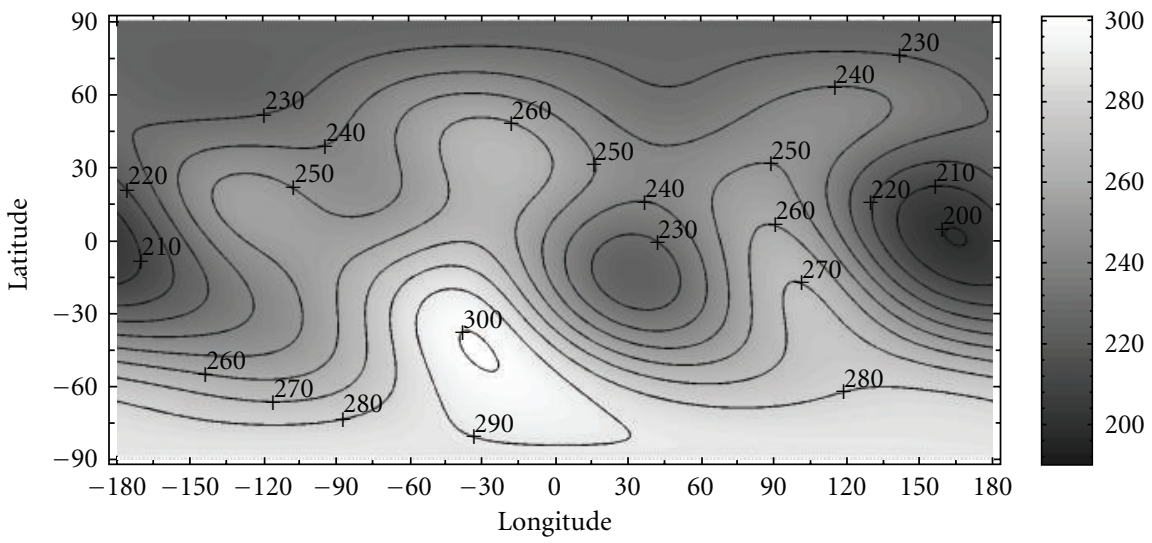

(b)

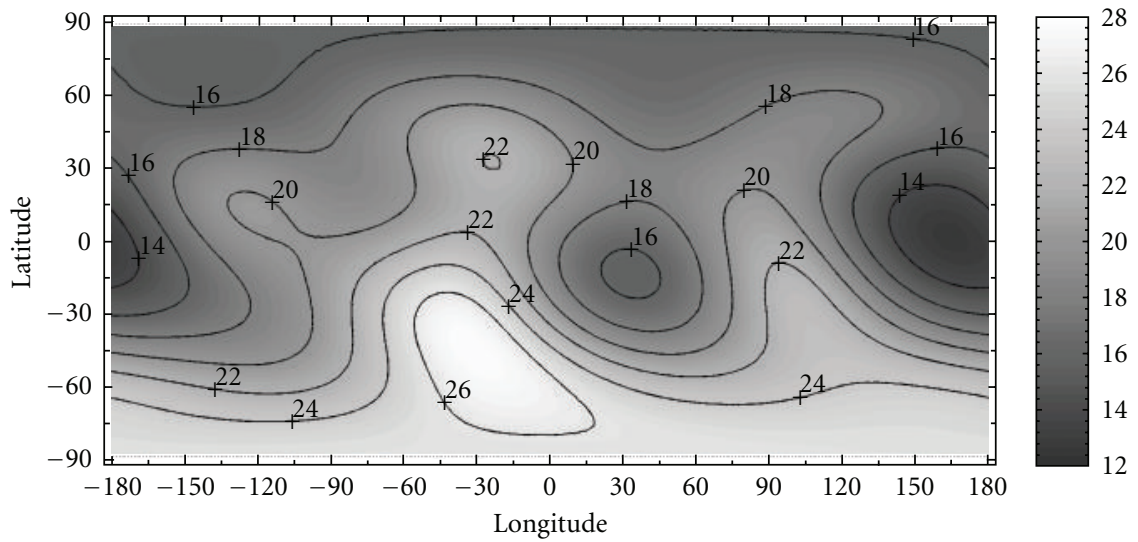

(c)

FIGURE 2: The global distributions of the atmospheric temperature $(\mathrm{K})$ at $110 \mathrm{~km}$ altitude, obtained from the NRLMSISE-00 empirical model for 16 January, UT $=10.30$ and calculated for two distinct values of solar activity: $F_{10.7}=101$ (a) and $F_{10.7}=230$ (b). Also the difference between the latter and the former distributions (c).

The model has the potential to describe the global neutral wind system under disturbed conditions when the vertical component of the neutral wind velocity at the levels of the lower thermosphere can be as large as several tens of meters per second [12-16].

The mathematical model, utilized in the present study, is based on the numerical solution of the system of equations containing the dynamical equation and continuity equation for the neutral gas. For solving the system of equations, the finite-difference method is applied. The dynamical equation for the neutral gas in vectorial form can be written as

$$
\rho\left(\frac{\partial \vec{V}}{\partial t}+(\vec{V}, \nabla) \vec{V}\right)=\rho \vec{F}+\nabla \cdot \hat{P}
$$




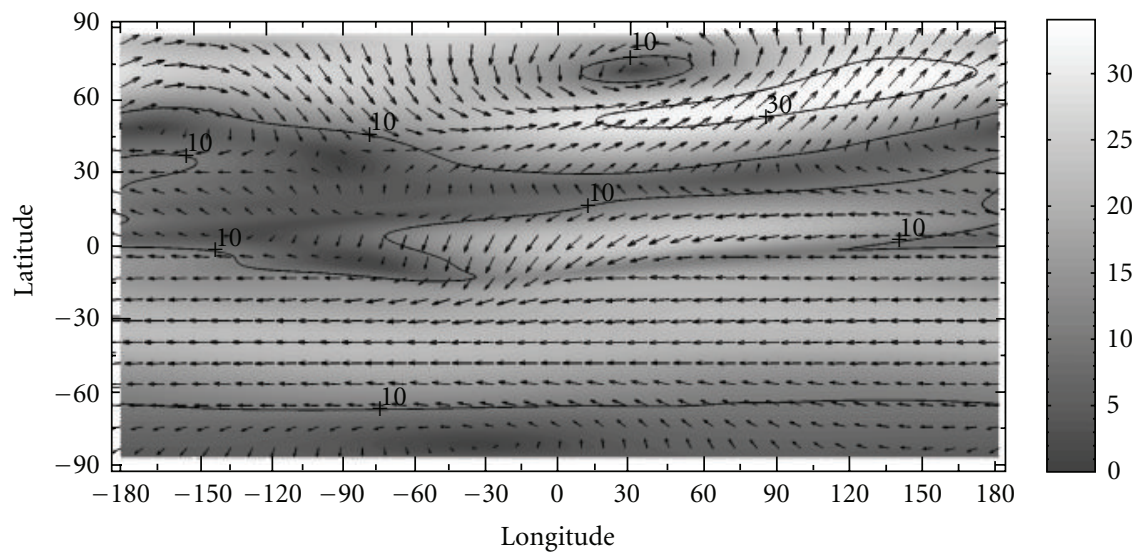

(a)

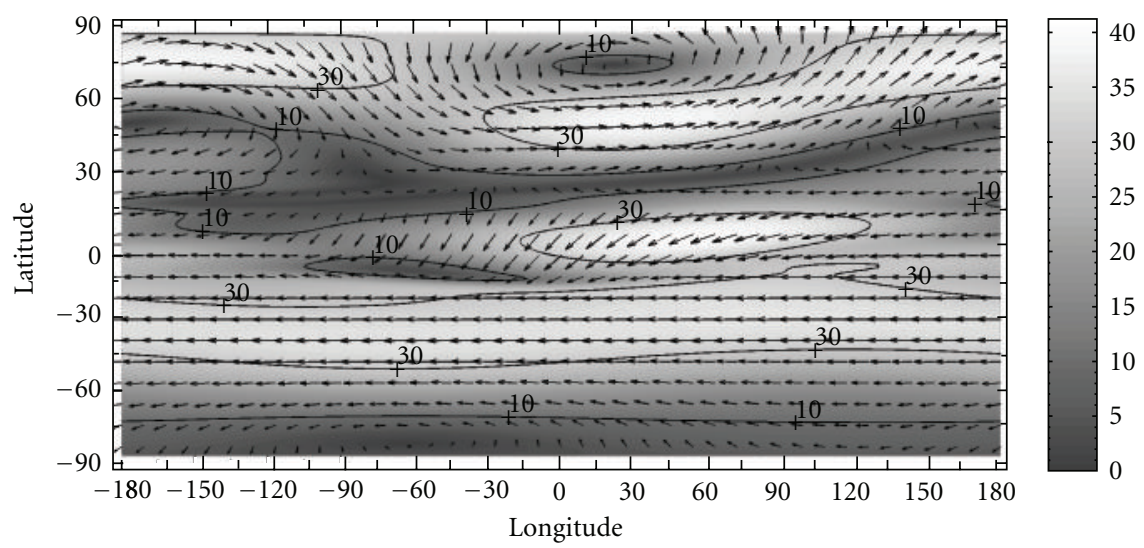

(b)

Figure 3: The global distributions of the vector of the simulated horizontal component of the neutral wind velocity at the altitude of $30 \mathrm{~km}$, obtained for 16 January and calculated for two distinct values of solar activity: $F_{10.7}=101$ (a) and $F_{10.7}=230$ (b). The velocities are given in $\mathrm{m} / \mathrm{s}$.

where $\rho$ is the neutral gas density, $\vec{V}$ is the neutral wind velocity, $\vec{F}$ is the acceleration comprising the gravity acceleration, Coriolis acceleration, acceleration of translation, and acceleration due to elastic collisions with the ion gas, and $\hat{P}$ is the total stress tensor. The latter tensor can be decomposed as follows:

$$
\hat{P}=-p \hat{I}+\hat{\tau}
$$

where $p$ is the pressure, $\bar{I}$ is the unit tensor, and $\hat{\tau}$ is the extra stress tensor whose components are given by the rheological equation of state or the law of viscous friction. A spherical coordinate system rotatable together with the earth is utilized in model calculations. Therefore, from the dynamical equation (1), momentum equations for the zonal, meridional, and vertical components of the neutral gas velocity may be derived. These equations include not only the pressure gradients but also partial derivatives of components of the extra stress tensor, $\hat{\tau}$. The latter tensor is composed of a Newtonian part, $\bar{\tau}_{0}$, and a complementary part, $\bar{\tau}_{1}$, namely,

$$
\hat{\tau}=\bar{\tau}_{0}+\bar{\tau}_{1}
$$

The former tensor, $\bar{\tau}_{0}$, is given by the well-known Newton's law of viscous friction,

$$
\hat{\tau}_{0}=2 \mu \hat{\varepsilon}
$$

where $\mu$ is the coefficient of molecular viscosity, whose dependence on the temperature is assumed to obey the Sutherland's law, and $\hat{\mathcal{\varepsilon}}$ is the tensor defined as

$$
\hat{\varepsilon}=\hat{D}_{0}-\frac{1}{3} \hat{I} \operatorname{Tr}\left(\hat{D}_{0}\right)
$$

where $\hat{D}_{0}$ is the strain rate tensor and $\operatorname{Tr}($ ) denotes the trace of a tensor. The complementary stress tensor, $\hat{\tau}_{1}$, is supposed to be conditioned by a small-scale turbulence having the scales equal and less than the steps of the finite-difference approximations. It is assumed that this tensor represents the effect of the turbulence on the mean flow and is given by an expression, analogous to the Newton's law of viscous friction (4), with the scalar coefficient of viscosity, $\mu$, being replaced by three distinct coefficients describing the eddy viscosities in the directions of the basis vectors of the utilized spherical coordinate system. For computing the eddy viscosities, the turbulence theory of Obukhov [21] is applied. 


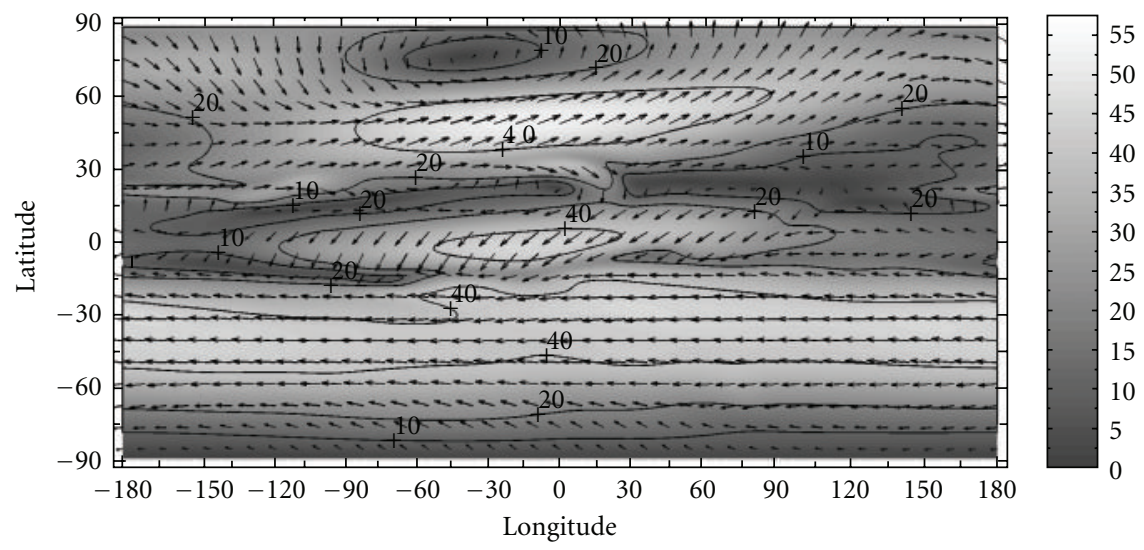

(a)

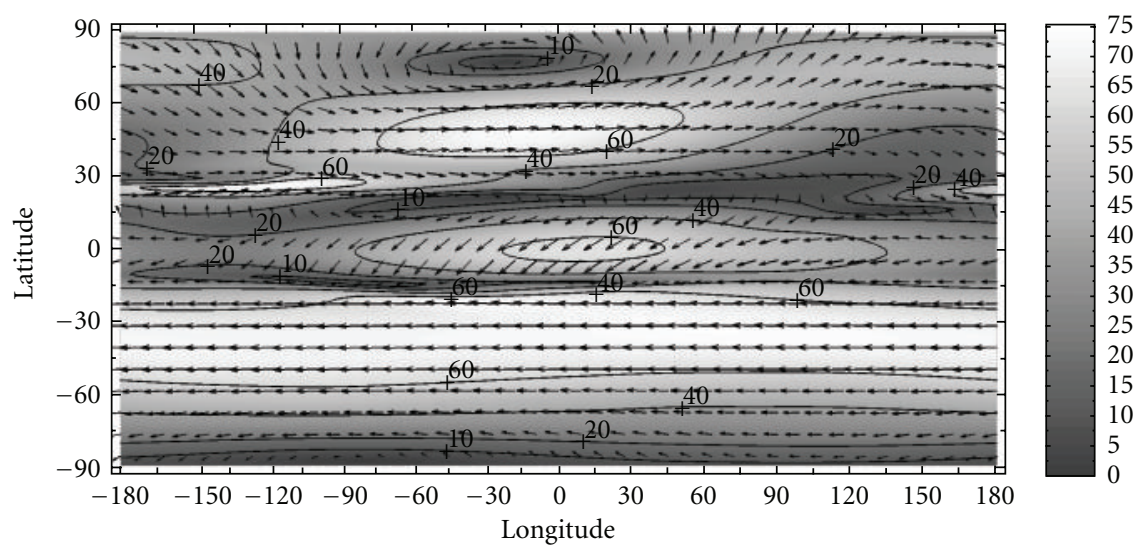

(b)

FIgure 4: The same as in Figure 3 but at the altitude of $50 \mathrm{~km}$.

Thus, the momentum equations for the zonal, meridional, and vertical components of the neutral gas velocity acquire ultimately a form of a generalized Navier-Stokes equation for compressible gas on scales which are more than the steps of the finite-difference approximations, with the effect of the turbulence on the mean flow being taken into account by using an empirical subgrid-scale parameterization. The steps of the finite-difference approximations in the latitude and longitude directions are identical and equal to 1 degree. The height step is nonuniform and does not exceed the value of $1 \mathrm{~km}$.

The simulation domain is the layer surrounding the earth globally and stretching from the ground up to the altitude of $126 \mathrm{~km}$ at the equator. Upper boundary conditions provide the conservation law of mass in the simulation domain. The earth's surface is supposed to coincide approximately with an oblate spheroid whose radius at the equator is more than that at the pole. More complete details of the utilized model may be found in the studies of I. V. Mingalev and V. S. Mingalev [17] and Mingalev et al. [18].

\section{Presentation and Discussion of Results}

The utilized mathematical model of the global neutral wind system can be used for different solar cycle, seasonal, and geomagnetic conditions. For the present study, calculations were made for low-geomagnetic activity $(\mathrm{Kp}=1)$ and for two different dates, namely, 16 January and 16 July, which belong to winter and summer in the northern hemisphere, respectively. To investigate the influence of solar activity on the global circulation of the atmosphere, we made calculations for conditions corresponding to two different $10.7 \mathrm{~cm}$ solar fluxes: moderate and high, namely, $F_{10.7}=$ 101 and 230. The variations of the atmospheric parameters with time were calculated until they become stationary. The steady-state distributions of the atmospheric parameters were obtained for two considered dates on condition that inputs to the model correspond to the identical moment (10.30 UT) for each day. The temperature distributions, corresponding to this moment, were taken for each day from the NRLMSISE-00 empirical model [20]. The NRLMSISE00 empirical atmospheric model extends from the ground to the exobase and is a major upgrade of the MSISE-90 model in the thermosphere. The model and the associated NRLMSIS database include the following data: (1) total mass density from satellite accelerometers and from orbit determination, (2) temperature from incoherent scatter radar covering 1981-1997, and (3) molecular oxygen number density, $\left[\mathrm{O}_{2}\right]$, from solar ultraviolet occultation aboard the Solar Maximum Mission. 


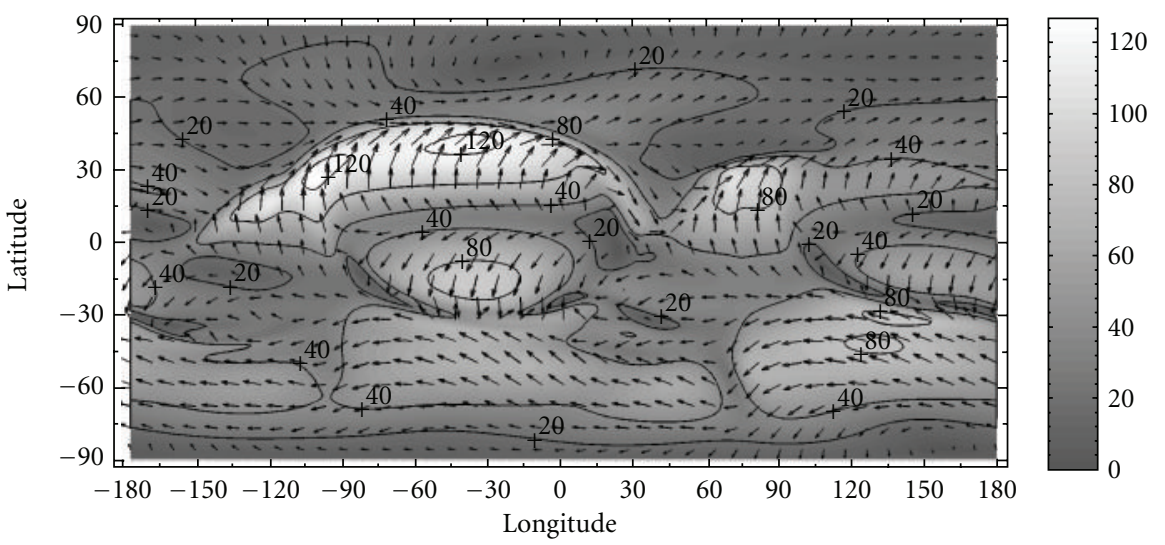

(a)

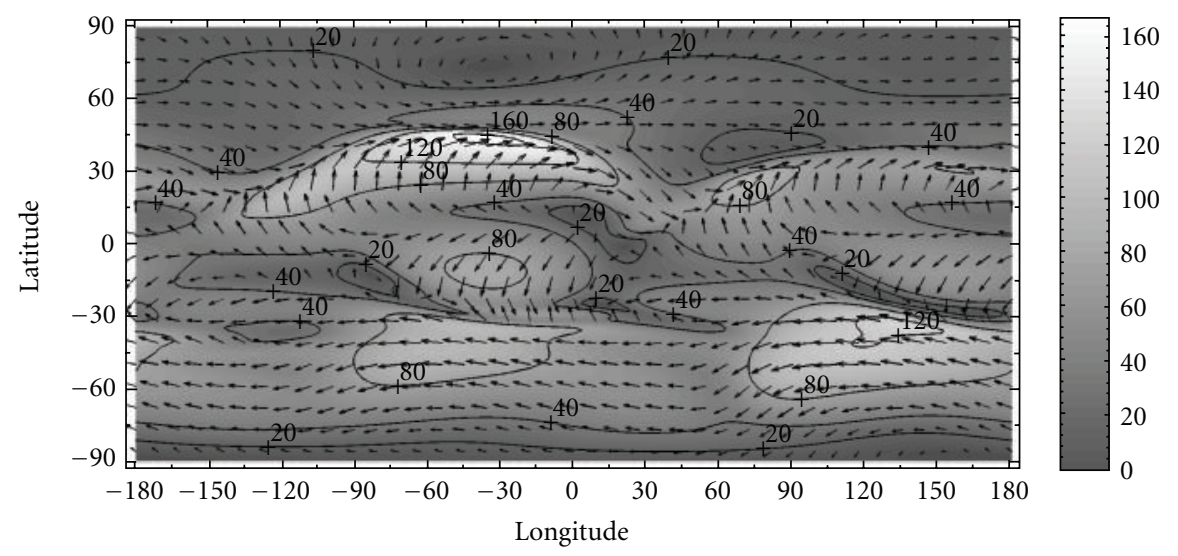

(b)

Figure 5: The same as in Figure 3 but at the altitude of $70 \mathrm{~km}$.

The numerical solutions to system of equations, described above, were obtained on condition that the boundary conditions and inputs to the model are time independent and correspondent to $10.30 \mathrm{UT}$. Since the obtained results are different, it is convenient to present them separately.

3.1. Simulation Results for January Conditions. Let us consider simulation results, obtained for the winter period in the northern hemisphere (16 January). The atmospheric temperature is one of major input parameters of the utilized mathematical model. As was noted earlier, in the present study, this input parameter is obtained from the NRLMSISE00 empirical model [20]. It turns out that atmospheric temperatures, calculated with the help of the NRLMSISE00 empirical model for two distinct values of solar activity $\left(F_{10.7}=101\right.$ and 230$)$, are very similar below approximately $100 \mathrm{~km}$, while, above this altitude, they may be rather different. This fact can be easy seen from Figures 1 and 2, with the planetary distributions of the atmospheric temperature being essentially nonuniform. From Figure 1, one can see that, at the altitude of $90 \mathrm{~km}$, temperatures, obtained for two considered $10.7 \mathrm{~cm}$ solar fluxes, are practically equal, with their differences being less than $0.001 \mathrm{~K}$ in whole simulation domain. From Figure 2, one can see that, at the altitude of
$110 \mathrm{~km}$, differences between temperatures, obtained for two considered $10.7 \mathrm{~cm}$ solar fluxes, can achieve a few tens of degrees at identical points of the globe. Thus, the application of the NRLMSISE-00 empirical model shows that the influence of level of solar activity on the global distribution of the atmospheric temperature ought to be absent at altitudes of the troposphere, stratosphere, and mesosphere, while this influence ought to be appreciable at altitudes of the lower thermosphere for the winter period in the northern hemisphere.

Distributions of the atmospheric parameters, calculated with the help of the mathematical model and obtained for 16 January, are shown in Figures 3-7. The results of modeling illustrate both common characteristic features and distinctions caused by different values of solar activity.

The calculated global distributions of the atmospheric parameters display the following common features. The horizontal and vertical components of the wind velocity are changeable functions of latitude and longitude at levels of the mesosphere and lower thermosphere. The horizontal domains exist where the steep gradients in the horizontal velocity field take place. The horizontal wind velocity can have various directions which may be opposite at the near points. Moreover, the horizontal domains exist in which 


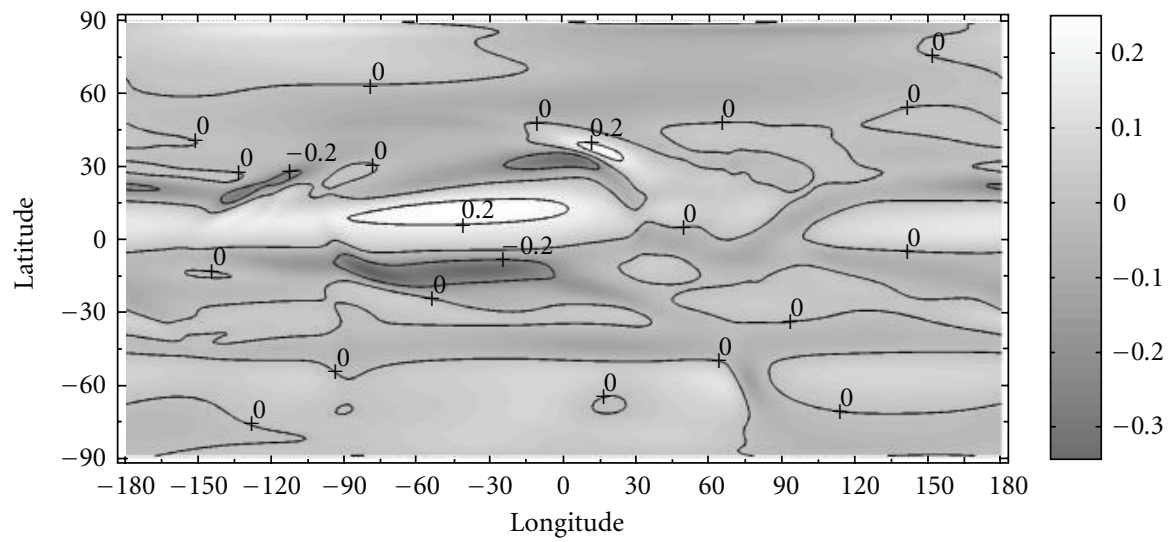

(a)

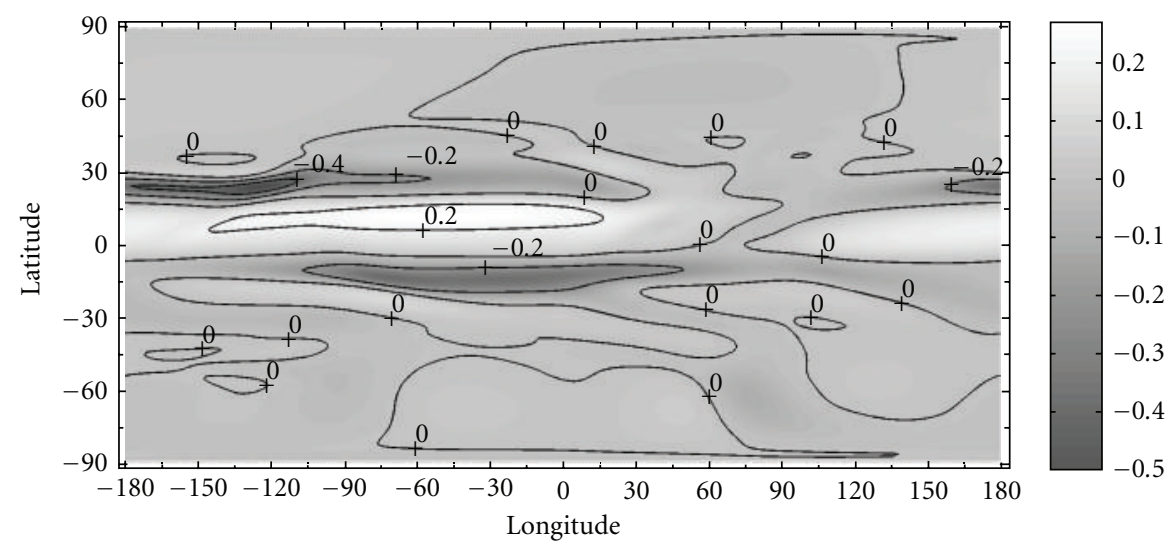

(b)

FIGURE 6: The global distributions of the simulated vertical component of the neutral wind velocity at the altitude of $50 \mathrm{~km}$, obtained for 16 January and calculated for two distinct values of solar activity: $F_{10.7}=101$ (a) and $F_{10.7}=230$ (b). The velocities are given in m/s, with positive direction of the vertical velocity being upward.

the vertical neutral wind component has opposite directions. Maximal absolute values of the horizontal and vertical components of the wind velocity are larger at higher altitudes. At levels of the mesosphere, the horizontal wind velocity can achieve values of more than $160 \mathrm{~m} / \mathrm{s}$.

From numerous observations, it is well known that circumpolar vortices are formed at heights of the stratosphere and mesosphere in the periods close to summer and winter solstices. The circumpolar cyclone arises in the northern hemisphere under winter conditions, while the circumpolar anticyclone arises in the southern hemisphere under summer conditions.

From the results shown in Figures 3-5, we can see that, for winter period in the northern hemisphere, at levels of the stratosphere and mesosphere, the motion of the neutral gas in the northern hemisphere is primarily eastward, so a circumpolar cyclone is formed. It can be noticed that the center of the northern cyclone may be displaced from the pole. Simultaneously, the motion of the neutral gas is primarily westward in the southern hemisphere at levels of the stratosphere and mesosphere, so a circumpolar anticyclone is formed for summer period of the southern hemisphere. It can be seen that the circumpolar vortices of the northern and southern hemispheres, simulated for moderate and high $10.7 \mathrm{~cm}$ solar fluxes for January conditions, correspond qualitatively to the global circulation, obtained from observations.

Let us consider simulation results, obtained for distinct values of solar activity and their distinctions. From Figure 3, one can see that, at the altitude of $30 \mathrm{~km}$, the horizontal component of the wind velocity in the circumpolar cyclone of the northern hemisphere, obtained for moderate solar activity, can achieve values of less than $35 \mathrm{~m} / \mathrm{s}$, while this component, obtained for high-solar activity, exceeds a value of $40 \mathrm{~m} / \mathrm{s}$. Thus, the horizontal wind velocity in the circumpolar cyclone of the northern hemisphere, obtained for moderate solar activity, is less than that obtained for high-solar activity. Similarly, the horizontal wind velocity in the circumpolar anticyclone of the southern hemisphere, obtained for moderate-solar activity, is less than that obtained for highsolar activity.

From Figure 3, it can be seen that, at low latitudes, the horizontal wind velocity, obtained for high-solar activity, can achieve values of more than $35 \mathrm{~m} / \mathrm{s}$, while this velocity, obtained for moderate solar activity, does not exceed a value of $25 \mathrm{~m} / \mathrm{s}$. Thus, at low latitudes, the horizontal wind velocity, 


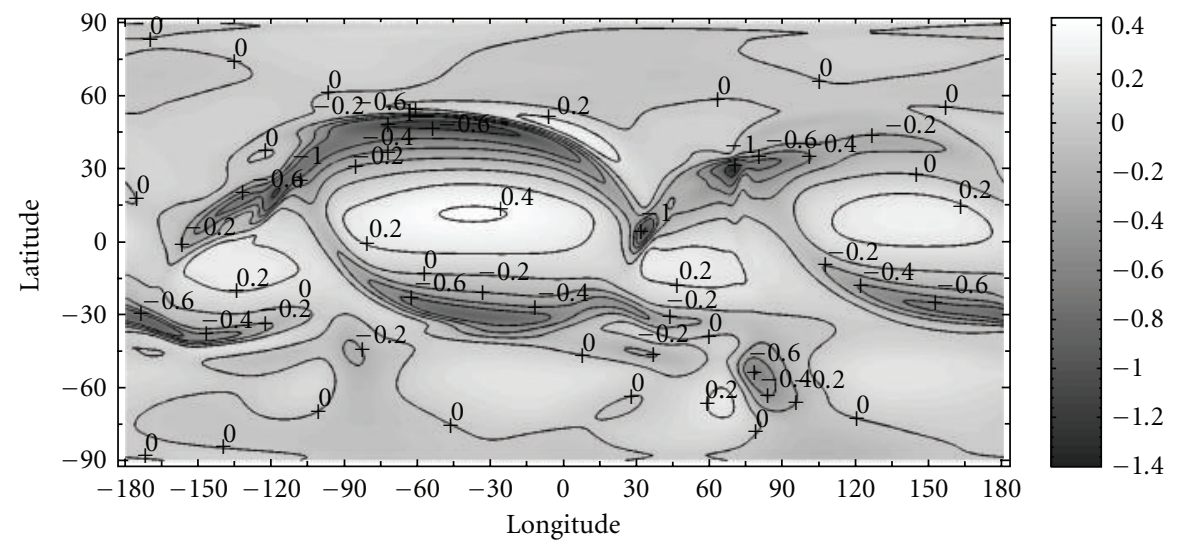

(a)

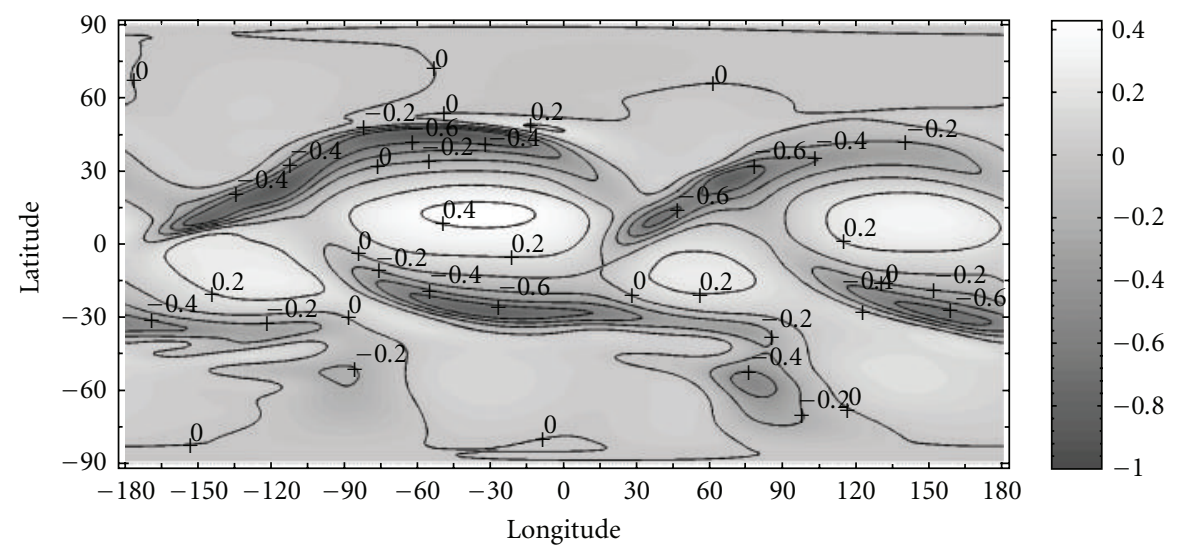

(b)

Figure 7: The same as in Figure 6 but at the altitude of $70 \mathrm{~km}$.

obtained for high-solar activity, is more than that obtained for moderate solar activity, at the altitude of $30 \mathrm{~km}$.

From Figures 4 and 5, we can see that maximal absolute values of the horizontal wind velocity, obtained for moderate-solar activity, are less than those, obtained for high-solar activity, at the altitudes of 50 and $70 \mathrm{~km}$.

From the results shown in Figures 6 and 7, we can see that, for winter period in the northern hemisphere, at levels of the mesosphere, the vertical wind velocity can have opposite directions in the horizontal domains having different configurations. Maximal absolute values of the downward vertical wind component are commensurable with the maximal module of the upward vertical wind component for conditions of moderate-solar activity. On the contrary, for conditions of high-solar activity, maximal absolute values of the downward and upward vertical wind components can be rather different. At low latitudes, maximal absolute values of the vertical wind velocity, obtained for moderate solar activity, are more than those, obtained for high-solar activity, at the altitudes of the mesosphere.

Simulation results, obtained for January conditions, indicate that despite of independence of the atmospheric temperature on the $10.7 \mathrm{~cm}$ solar flux below approximately $100 \mathrm{~km}$, the influence of the solar activity level on the global circulation of the stratosphere and mesosphere does exist. This influence is a consequence of a relationship between largescale circulations of the middle atmosphere and thermosphere, with the thermospheric circulation being dependent on the solar activity level, undoubtedly. The influence is conditioned by the vertical transport of air from the lower thermosphere to the mesosphere and stratosphere. This transport may be rather different under distinct solar activity conditions.

3.2. Simulation Results for July Conditions. Now, let us consider simulation results, obtained for the summer period in the northern hemisphere (16 July). The atmospheric temperatures, calculated with the help of the NRLMSISE-00 empirical model for two distinct values of solar activity $\left(F_{10.7}=\right.$ 101 and 230), are identical below $100 \mathrm{~km}$. However, above this altitude they may be rather different at the same points of the globe. As can be seen from Figure 8, the differences between temperatures, obtained for two considered $10.7 \mathrm{~cm}$ solar fluxes, can achieve values of more than $30 \mathrm{~K}$ at the altitude of $110 \mathrm{~km}$. Thus, the influence of solar activity on the global distributions of the atmospheric temperature, calculated with the help of the NRLMSISE-00 empirical 


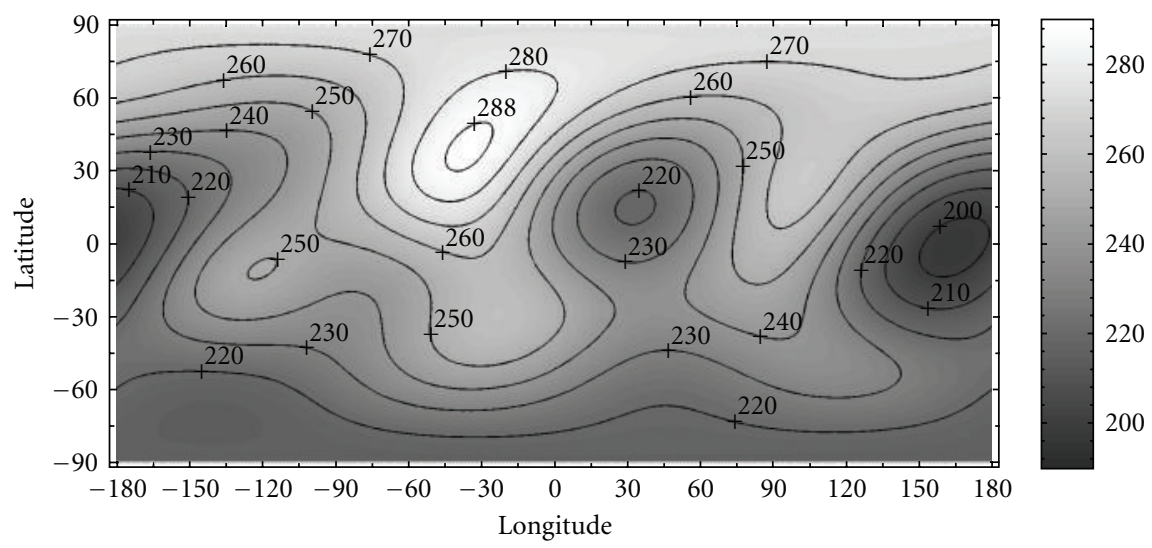

(a)

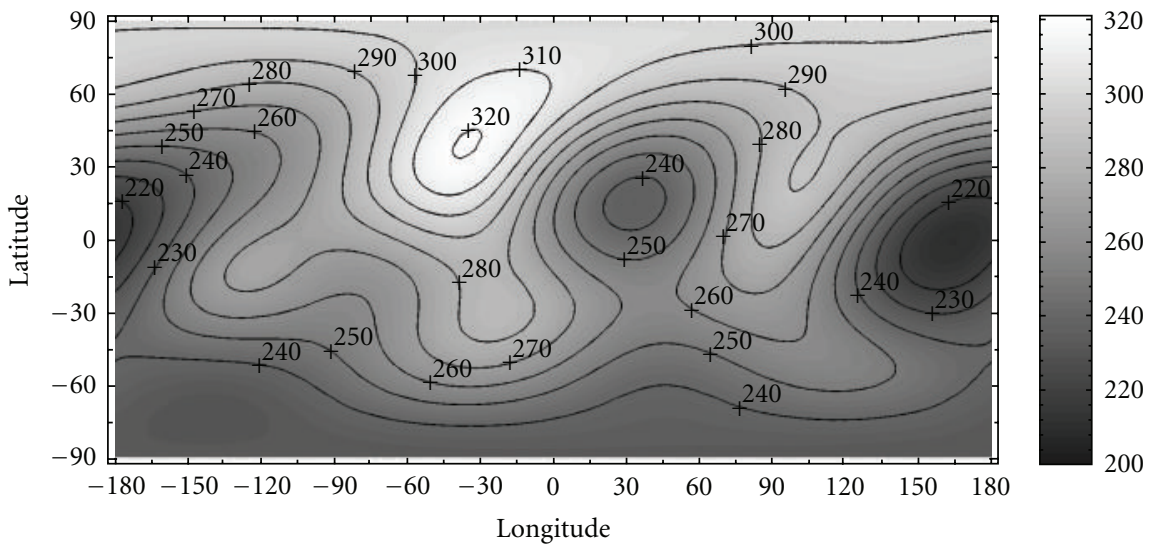

(b)

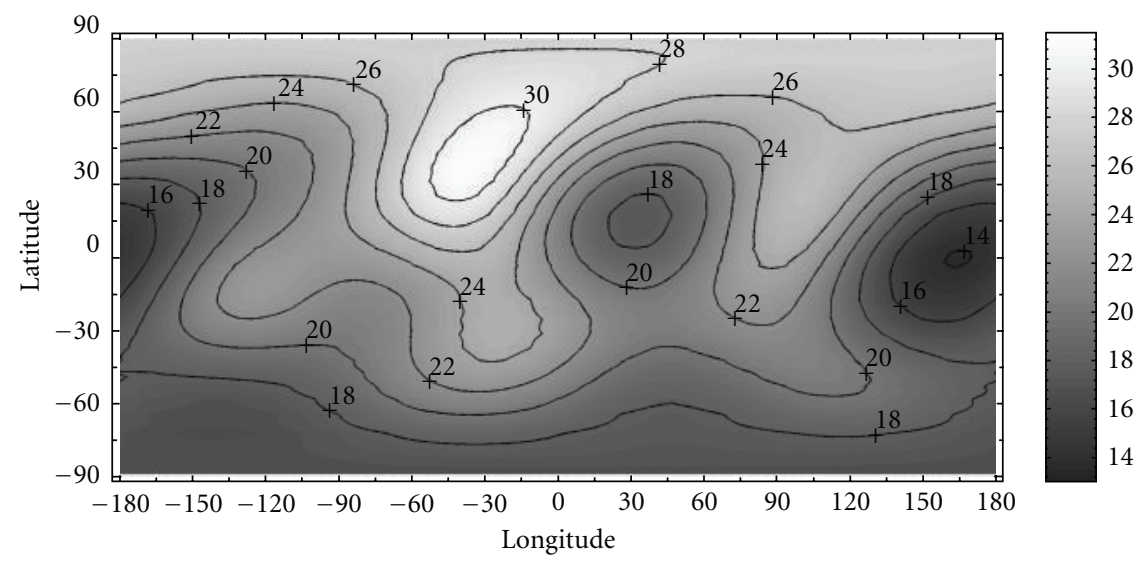

(c)

FIGURE 8: The global distributions of the atmospheric temperature $(\mathrm{K})$ at $110 \mathrm{~km}$ altitude, obtained from the NRLMSISE-00 empirical model for 16 July, UT $=10.30$ and calculated for two distinct values of solar activity: $F_{10.7}=101$ (a) and $F_{10.7}=230$ (b). Also the difference between the latter and the former distributions (c).

model, ought to be absent below $100 \mathrm{~km}$ for the summer period in the northern hemisphere.

The results of modeling, obtained for 16 July, are shown in Figures 9-13. These results illustrate common characteristic features which, in essence, are the same as in January conditions, described in the previous subsection. The simulation results, presented in Figures 9 and 10, indicate that, for the summer period in the northern hemisphere, at levels of the stratosphere and mesosphere, the motion of the neutral gas in the northern hemisphere is primarily westward, so a circumpolar anticyclone is formed. Simultaneously, the motion of the neutral gas is primarily eastward 


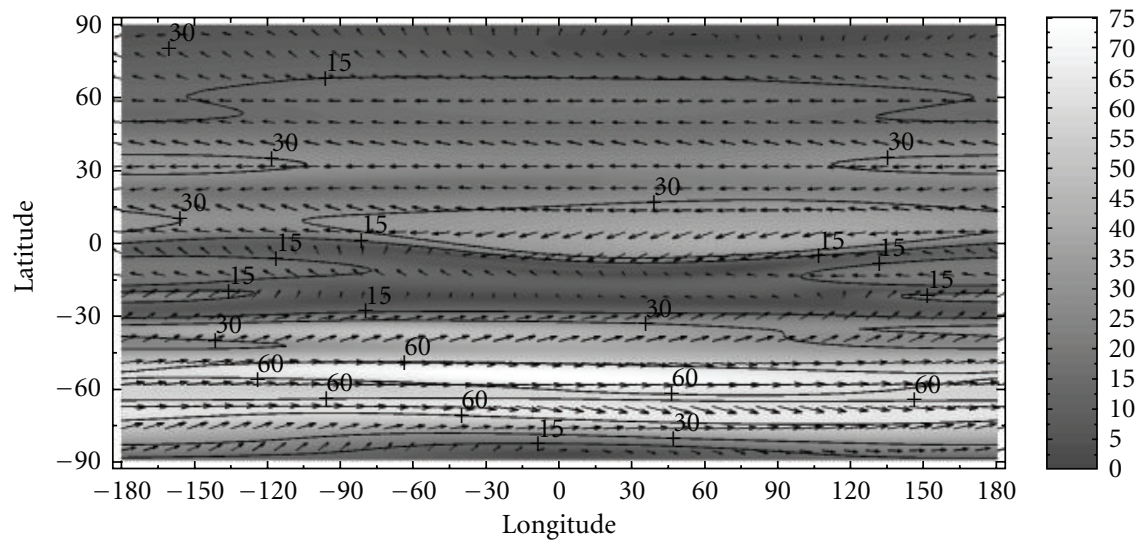

(a)

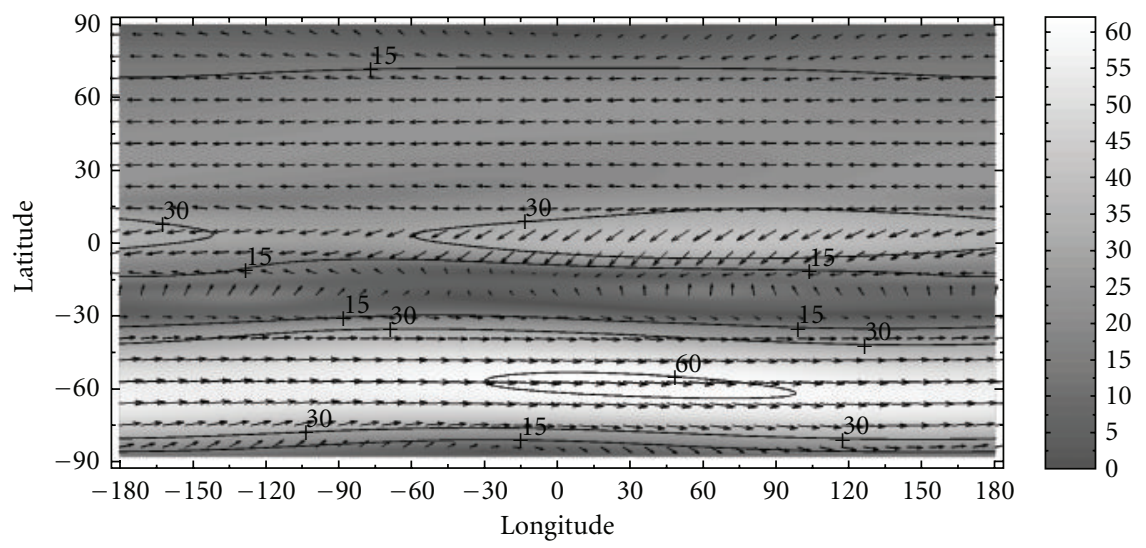

(b)

FIGURE 9: The global distributions of the vector of the simulated horizontal component of the neutral wind velocity at the altitude of $30 \mathrm{~km}$, obtained for 16 July and calculated for two distinct values of solar activity: $F_{10.7}=101$ (a) and $F_{10.7}=230$ (b). The velocities are given in m/s.

in the southern hemisphere at levels of the stratosphere and mesosphere, so a circumpolar cyclone is formed for winter period of the southern hemisphere.

From numerous observations, it is known that a circumpolar anticyclone arises in the northern hemisphere under summer conditions, while the circumpolar cyclone arises in the southern hemisphere under winter conditions. It is easy to see that the circumpolar vortices of the northern and southern hemispheres, simulated for moderate and high $10.7 \mathrm{~cm}$ solar fluxes for July conditions, correspond qualitatively to the global circulation, obtained from observations.

From the results shown in Figures 9 and 10, we can see that the horizontal wind velocity in the circumpolar cyclone of the southern hemisphere, obtained for moderatesolar activity, is more than that obtained for high-solar activity. Also, from Figure 9, it can be seen that, at low latitudes, the westward horizontal wind velocity, obtained for moderate solar-activity, is more than that obtained for high-solar activity, at the altitude of $30 \mathrm{~km}$. From Figure 10, it can be seen that, close to a latitude of $-30^{\circ}$, a long narrow band exists in which the horizontal component of the wind velocity, calculated for high-solar activity, can achieve values of more than $110 \mathrm{~m} / \mathrm{s}$. This peculiarity is absent in the results, calculated for moderate-solar activity. From Figure 11, we can see that maximal absolute values of the horizontal wind velocity, obtained for moderate-solar activity, are more than those, obtained for high-solar activity, at the altitude of $90 \mathrm{~km}$. As it is seen from Figures 12 and 13, at levels of the mesosphere and lower thermosphere, the vertical wind velocity, calculated for the summer period in the northern hemisphere, can have opposite directions in the horizontal domains having different configurations. The horizontal domains, where the vertical wind component is downward, are similar to a long narrow band, while the horizontal domains, where the vertical component of the neutral wind is upward, are similar to a spot having a great length and large width.

From the results shown in Figure 12, we can see that maximal values of the upward vertical wind component, calculated for both moderate- and high-solar activities, are approximately equal at the altitude of $50 \mathrm{~km}$. On the contrary, maximal values of the downward vertical wind component, calculated for high-solar activity, are more than those obtained for moderate-solar activity, at the altitude of $50 \mathrm{~km}$. From Figure 13, we can see that maximal absolute values of the vertical wind velocity can achieve magnitudes 


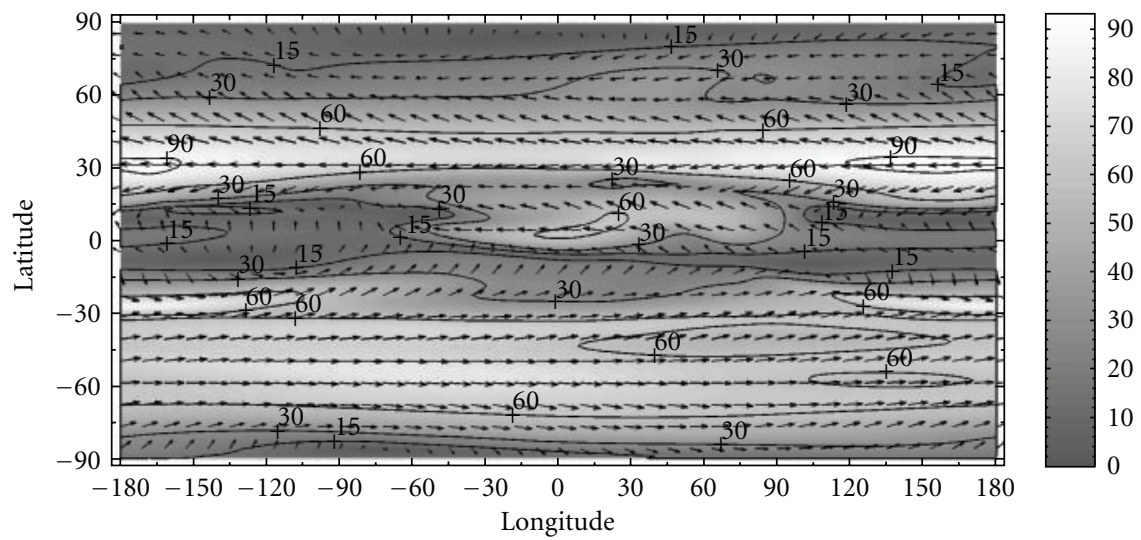

(a)

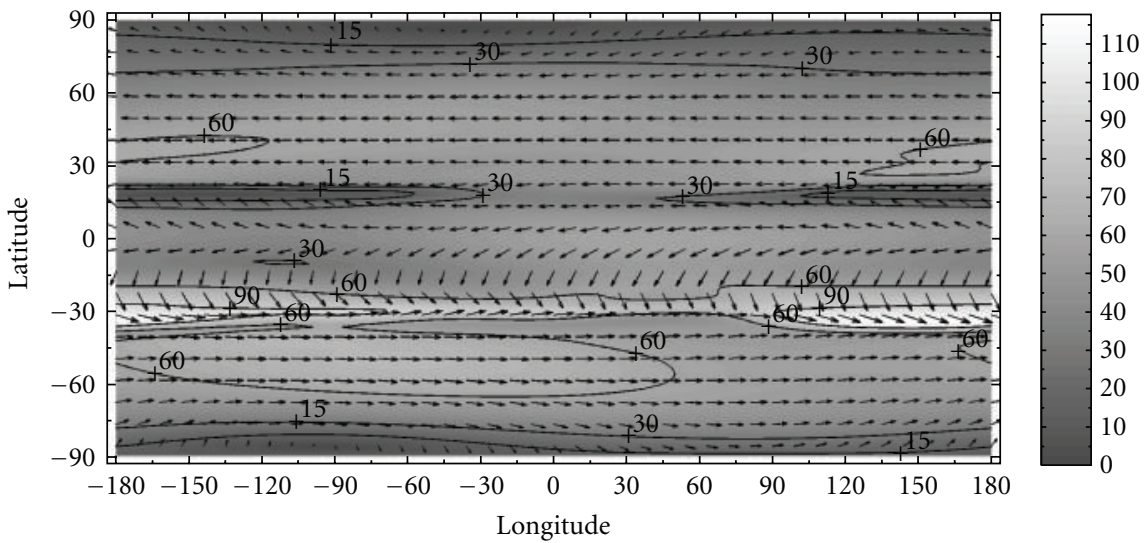

(b)

FIgURE 10: The same as in Figure 9 but at the altitude of $50 \mathrm{~km}$.

of about $2 \mathrm{~m} / \mathrm{s}$ at the altitude of $90 \mathrm{~km}$. It is doubtful that such magnitudes may be simulated by general circulation models applying the hydrostatic approach. On the contrary, it may be expected that such magnitudes may be simulated by nonhydrostatic general circulation models, in particular by the Whole Atmosphere Community Climate Model (WACCM), utilized in the study of Smith et al. [22].

From the simulation results, obtained for the summer period in the northern hemisphere, we can see that the atmospheric temperature, calculated with the help of the NRLMSISE-00 empirical model, does not depend on the $10.7 \mathrm{~cm}$ solar flux below approximately $100 \mathrm{~km}$. Nevertheless, below $100 \mathrm{~km}$, the effect of solar activity on the global circulation of the atmosphere does exist. This effect is conditioned by a relationship between circulations of middle atmosphere and thermosphere. A variation of the $10.7 \mathrm{~cm}$ solar flux leads to changes of large-scale circulation of the thermosphere, in particular, the vertical wind, which can penetrate to low altitudes and affect the global circulation of the mesosphere and stratosphere.

\section{Summary and Conclusions}

The nonhydrostatic model of the global neutral wind system of the earth's atmosphere, developed earlier in the Polar
Geophysical Institute, was utilized to investigate how solar activity affects the formation of the large-scale global circulation of the mesosphere and lower thermosphere. The applied mathematical model differs essentially from existing global circulation models of the atmosphere. Firstly, an internal energy equation for the neutral gas is not included in the applied mathematical model. Instead, the global temperature field is assumed to be a given distribution, that is, the input parameter of the model and obtained from the NRLMSISE00 empirical model [20]. Secondly, the vertical component of the neutral wind velocity is calculated without using the hydrostatic equation. The vertical component of the neutral wind velocity as well as the horizontal components is obtained by means of a numerical solution of a generalized Navier-Stokes equation for compressible gas, with whatever restrictions on the vertical transport of the neutral gas being absent.

The applied mathematical model was utilized for obtaining the steady-state distributions of the atmospheric parameters, using the method of establishment, for conditions, corresponding to two different dates, namely, 16 January and 16 July, for the identical moment (10.30 UT) for each considered day. Calculations were performed for low-geomagnetic activity and for conditions corresponding to two different 


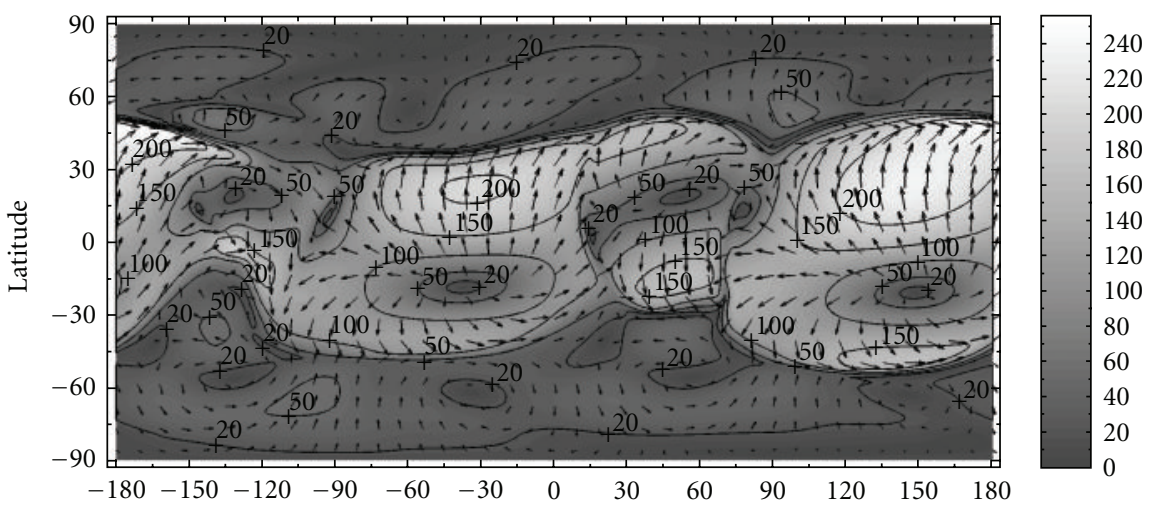

(a)

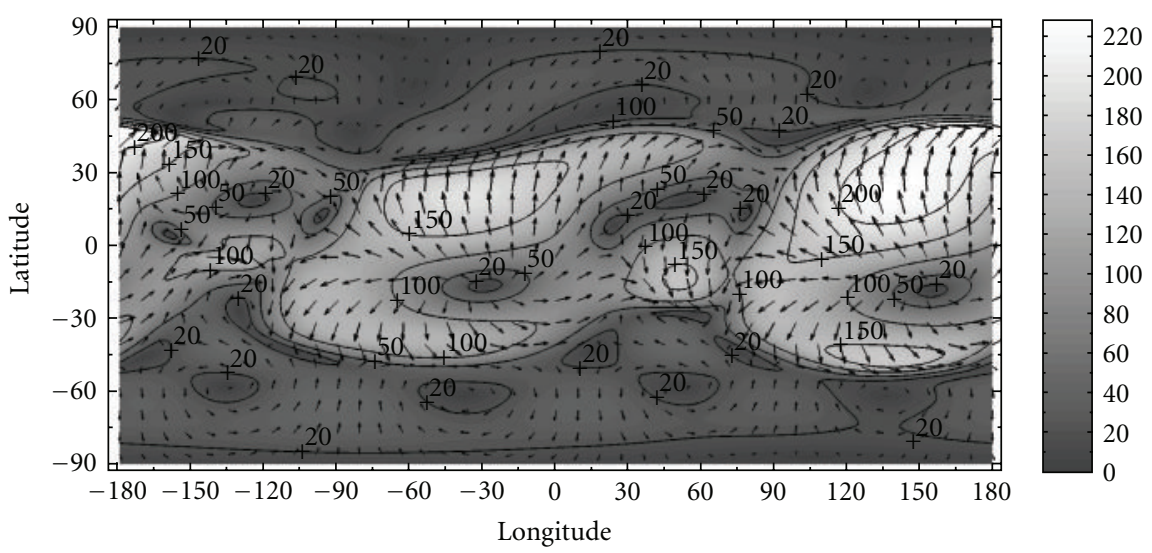

(b)

FIgURE 11: The same as in Figure 9 but at the altitude of $90 \mathrm{~km}$.

$10.7 \mathrm{~cm}$ solar fluxes: moderate and high, namely, $F_{10.7}=101$ and 230 .

The results of simulation illustrate common characteristic features. In particular, the calculated horizontal and vertical components of the wind velocity are changeable functions of latitude and longitude at levels of the mesosphere and lower thermosphere. It turned out that the calculated global distributions of the horizontal wind velocity, obtained for different dates and solar activity levels, contain largescale circumpolar vortices of the northern and southern hemispheres. It turned out that, in the northern hemisphere, the circumpolar cyclone is formed under winter conditions and the circumpolar anticyclone is formed under summer conditions. In the southern hemisphere, the circumpolar anticyclone is formed in January and the circumpolar cyclone is formed in July. It should be emphasized that the circumpolar vortices of the northern and southern hemispheres, obtained using the mathematical model at levels of the mesosphere for January and July conditions, are consistent with existing observational data. This fact manifests the adequacy of the mathematical model utilized in the present study.

The simulation results, obtained for January conditions, indicated that solar activity ought to influence considerably on the formation of global neutral wind system in the mesosphere and lower thermosphere. In both northern and southern hemispheres, above approximately $25 \mathrm{~km}$, maximal absolute values of the horizontal wind velocity, obtained for moderate-solar activity, ought to be less than those, obtained for high-solar activity. At low latitudes, maximal absolute values of the horizontal wind velocity, obtained for high solar activity, ought to be more than those, obtained for moderate solar activity, at altitudes of more than $25 \mathrm{~km}$. At low latitudes, maximal absolute values of the vertical component of the wind velocity, obtained for moderate-solar activity, ought to be more than those, obtained for high-solar activity, at altitudes of the mesosphere.

The simulation results, obtained for July conditions, possess the following characteristic features. In the northern hemisphere, below approximately $40 \mathrm{~km}$, maximal absolute values of the horizontal wind velocity, obtained for moderate-solar activity, ought to be less than those, obtained for high-solar activity, while, above this altitude, these values, obtained for moderate-solar activity, ought to be more than ones, obtained for high-solar activity. In the southern hemisphere, below approximately $40 \mathrm{~km}$, maximal absolute values of the horizontal wind velocity, obtained for moderate-solar activity, ought to be more than those, obtained for high-solar 


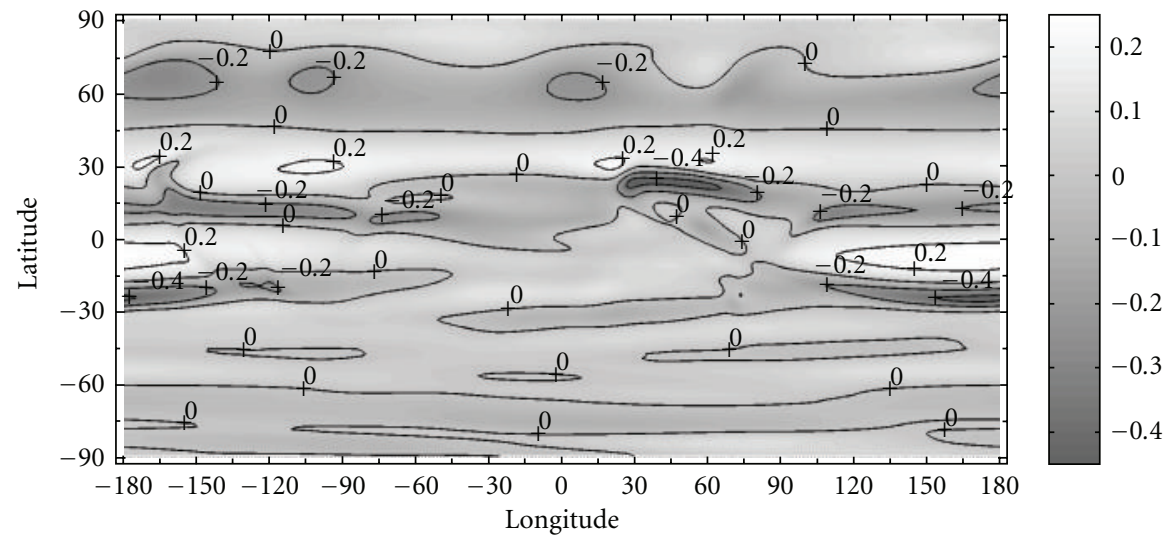

(a)

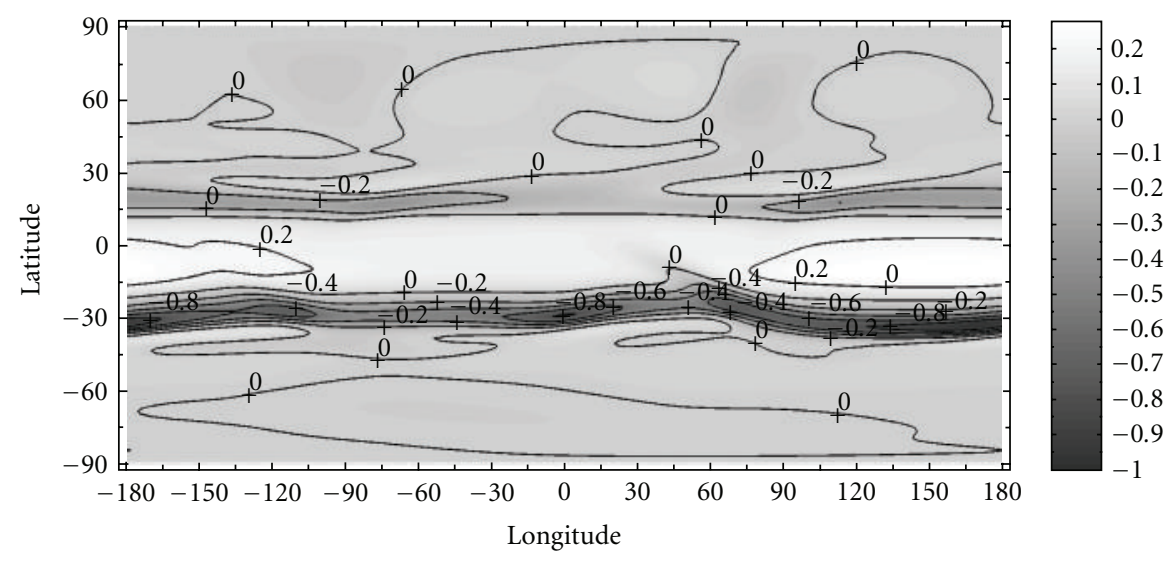

(b)

FIGURE 12: The global distributions of the simulated vertical component of the neutral wind velocity at the altitude of $50 \mathrm{~km}$, obtained for 16 July and calculated for two distinct values of solar activity: $F_{10.7}=101$ (a) and $F_{10.7}=230$ (b). The velocities are given in m/s, with positive direction of the vertical velocity being upward.

activity, while, above this altitude, these values, obtained for moderate-solar activity, ought to be less than ones, obtained for high-solar activity. At low latitudes, below approximately $25 \mathrm{~km}$, maximal absolute values of the horizontal wind velocity, obtained for moderate-solar activity, ought to be less than those, obtained for high-solar activity, while, above this altitude, these values, obtained for moderate-solar activity, ought to be more than ones, obtained for high-solar activity.

From the simulation results presented, we can see that the atmospheric temperature, calculated with the help of the NRLMSISE-00 empirical model, does not depend on the $10.7 \mathrm{~cm}$ solar flux below approximately $100 \mathrm{~km}$. Nevertheless, the effect of solar activity on the global circulation of the atmosphere below $100 \mathrm{~km}$ does exist. This effect is conditioned by a relationship between global circulations of the thermosphere and middle atmosphere. In this relationship, a vertical motion of air can play a significant role. At altitudes of more than $100 \mathrm{~km}$, the global distributions of the atmospheric temperatures, calculated for distinct $10.7 \mathrm{~cm}$ solar fluxes, are different. As a consequence, correspondent global circulations of the atmosphere at these altitudes are different, too, including the vertical wind system. Since the vertical wind can penetrate to low altitudes, the global circulation of the mesosphere and stratosphere may be transformed. In this way, the influence of solar activity on the global circulation of the mesosphere and stratosphere is primarily realized. Incidentally, the utilized mathematical model was able to simulate this influence due to the fact that the model is nonhydrostatic.

It can be noticed that the point of view exists that the atmospheric temperature ought to depend on the $10.7 \mathrm{~cm}$ solar flux below $100 \mathrm{~km}$ (e.g., see [23, 24]). However, such dependence is not reproduced by the NRLMSISE-00 empirical model as well as by other existing empirical models of the global distributions of the atmospheric temperature. Nevertheless, the application of the NRLMSISE-00 empirical model leads to the effect of solar activity on the global circulation of the atmosphere below $100 \mathrm{~km}$ due to the vertical transport of air from the lower thermosphere to the mesosphere and stratosphere. It may be expected that, taking into consideration the dependence of atmospheric temperature on the $10.7 \mathrm{~cm}$ solar flux below $100 \mathrm{~km}$, one can obtain in future a more pronounced effect of solar activity on the global circulation of the atmosphere below $100 \mathrm{~km}$. 


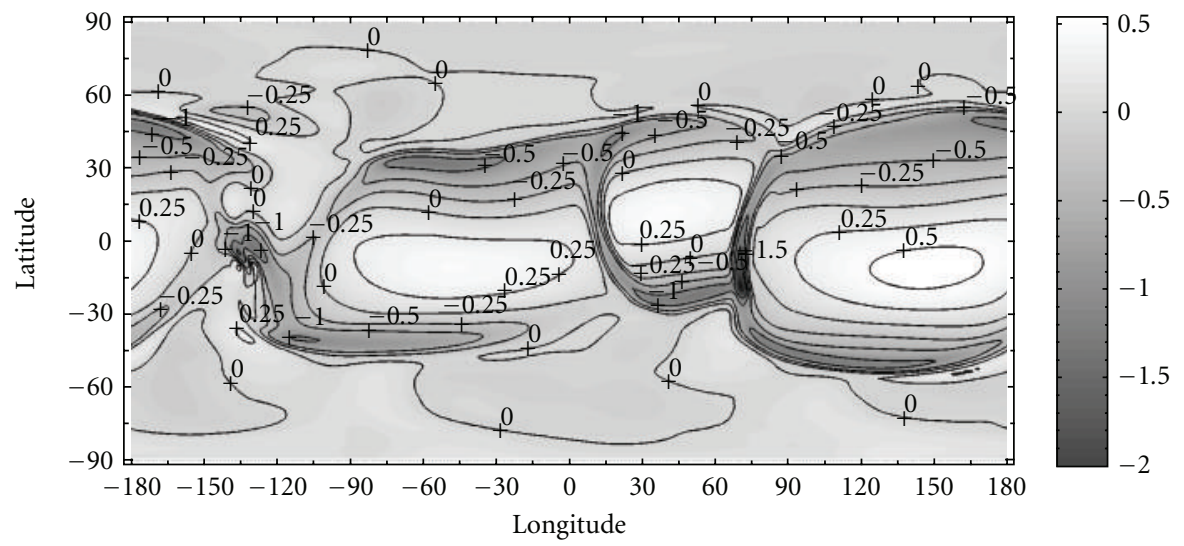

(a)

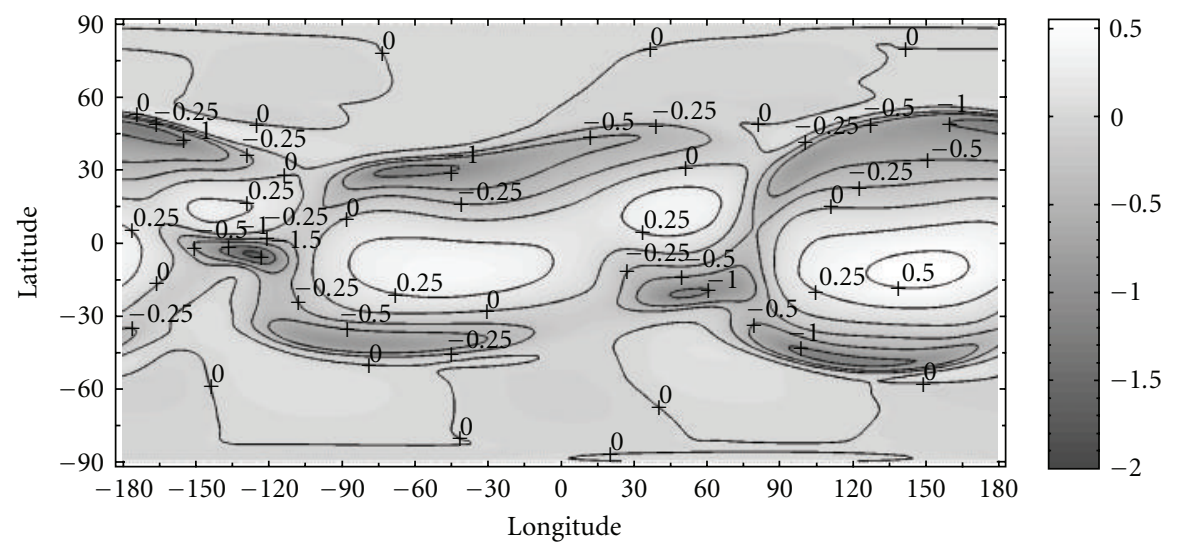

(b)

Figure 13: The same as in Figure 12 but at the altitude of $90 \mathrm{~km}$.

\section{Acknowledgments}

This work was partly supported by Grant no. 10-01-00451 from the Russian Foundation for Basic Research. The authors would like to thank the reviewers for helpful suggestions that led to improvement in the original paper.

\section{References}

[1] S. Manabe and D. G. Hahn, "Simulation of atmospheric variability," Monthly Weather Review, vol. 109, no. 11, pp. 22602286, 1981.

[2] D. Cariolle, A. Lasserre-Bigorry, J. F. Royer, and J. F. Geleyn, "A general circulation model simulation of the springtime antarctic ozone decrease and its impact on mid-latitudes," Journal of Geophysical Research, vol. 95, no. 2, pp. 1883-1898, 1990.

[3] P. J. Rasch and D. L. Williamson, "The sensitivity of a general circulation model climate to the moisture transport formulation," Journal of Geophysical Research, vol. 96, article D7, pp. 123-137, 1991.

[4] H. F. Graf, I. Kirchner, R. Sausen, and S. Schubert, "The impact of upper-tropospheric aerosol on global atmospheric circulation," Annales Geophysicae, vol. 10, pp. 689-707, 1992.

[5] P. A. Stott and R. S. Harwood, "An implicit time-stepping scheme for chemical species in a Global atmospheric circulation model," Annales Geophysicae, vol. 11, pp. 377-388, 1993.
[6] B. Christiansen, A. Guldberg, A. W. Hansen, and L. P. Riishojgaard, "On the response of a three-dimensional general circulation model to imposed changes in the ozone distribution," Journal of Geophysical Research D, vol. 102, no. 11, pp. 13051-13077, 1997.

[7] V. Y. Galin, "Parametrization of radiative processes in the DNM atmospheric model," Izvestiya, Atmospheric and Ocean Physics, vol. 34, no. 3, pp. 339-347, 1998 (Russian).

[8] A. L. Gibelin and M. Déqué, "Anthropogenic climate change over the mediterranean region simulated by a global variable resolution model," Climate Dynamics, vol. 20, no. 4, pp. 327$339,2002$.

[9] M. Mendillo, H. Rishbeth, R. G. Roble, and J. Wroten, "Modelling f2-layer seasonal trends and day-to-day variability driven by coupling with the lower atmosphere," Journal of Atmospheric and Solar-Terrestrial Physics, vol. 64, no. 18, pp. 1911-1931, 2002.

[10] M. J. Harris, N. F. Arnold, and A. D. Aylward, "A study into the effect of the diurnal tide on the structure of the background mesosphere and thermosphere using the new coupled middle atmosphere and thermosphere (cmat) general circulation model," Annales Geophysicae, vol. 20, no. 2, pp. 225-235, 2002.

[11] U. Langematz, A. Claussnitzer, K. Matthes, and M. Kunze, "The climate during the maunder minimum: a simulation with the freie universität berlin climate middle atmosphere 
model (fub-cmam)," Journal of Atmospheric and Solar-Terrestrial Physics, vol. 67, no. 1-2, pp. 55-69, 2005.

[12] S. Peteherych, G. G. Shepherd, and J. K. Walker, "Observation of vertical e-region neutral winds in two intense auroral arcs," Planetary and Space Science, vol. 33, no. 8, pp. 869-873, 1985.

[13] H. U. Widdel, "Vertical movements in the middle atmosphere derived from foil cloud experiments," Journal of Atmospheric and Terrestrial Physics, vol. 49, no. 7-8, pp. 723-741, 1987.

[14] U. P. Hoppe and T. Hansen, "Studies of vertical motions in the upper mesosphere using the EISCAT UHF radar," Annales Geophysicae, vol. 6, pp. 181-186, 1988.

[15] G. D. Price and F. Jacka, "The influence of geomagnetic activity on the upper mesosphere/lower thermosphere in the auroral zone. i. vertical winds," Journal of Atmospheric and Terrestrial Physics, vol. 53, no. 10, pp. 909-922, 1991.

[16] M. Ishii, "Relationship between thermospheric vertical wind and the location of ionospheric current in the polar region," Advances in Polar Upper Atmosphere Research, vol. 19, pp. 6370, 2005.

[17] I. V. Mingalev and V. S. Mingalev, "The global circulation model of the lower and middle atmosphere of the Earth with a given temperature distribution," Mathematical Modeling, vol. 17, pp. 24-40, 2005 (Russian).

[18] I. V. Mingalev, V. S. Mingalev, and G. I. Mingaleva, "Numerical simulation of the global distributions of the horizontal and vertical wind in the middle atmosphere using a given neutral gas temperature field," Journal of Atmospheric and SolarTerrestrial Physics, vol. 69, no. 4-5, pp. 552-568, 2007.

[19] I. V. Mingalev, O. V. Mingalev, and V. S. Mingalev, "Model simula-tion of the global circulation in the middle atmosphere for january conditions," Advances in Geosciences, vol. 15, pp. 11-16, 2008.

[20] J. M. Picone, A. E. Hedin, D. P. Drob, and A. C. Aikin, "Nrlmsise-00 empirical model of the atmosphere: statistical comparisons and scientific issues," Journal of Geophysical Research A, vol. 107, no. 12, article 1468, 16 pages, 2002.

[21] A. M. Obukhov, Turbulence and Dynamics of Atmosphere, Hydrometeoizdat, Leningrad, Russia, 1988.

[22] A. K. Smith, R. R. Garcia, D. R. Marsh, and J. H. Richter, "WACCM simulations of the mean circulation and trace species transport in the winter mesosphere," Journal of Geophysical Research D, vol. 116, no. 20, Article ID D20115, 17 pages, 2011.

[23] R. E. Cahalan, G. Wen, J. W. Harder, and P. Pilewskie, “Temperature responses to spectral solar variability on decadal time scales," Geophysical Research Letters, vol. 37, Article ID L07705, 5 pages, 2010.

[24] A. I. Semenov, N. N. Shefov, and V. A. Sukhodoev, "Re-analysis of the long-term hydroxyl rotational temperature trend according to measurements in Spitsbergen," in Proceedings of the 29th Annual Seminar on Physics of Auroral Phenomena, Polar Geophysical Institute, Apatity, Russia, 2007. 

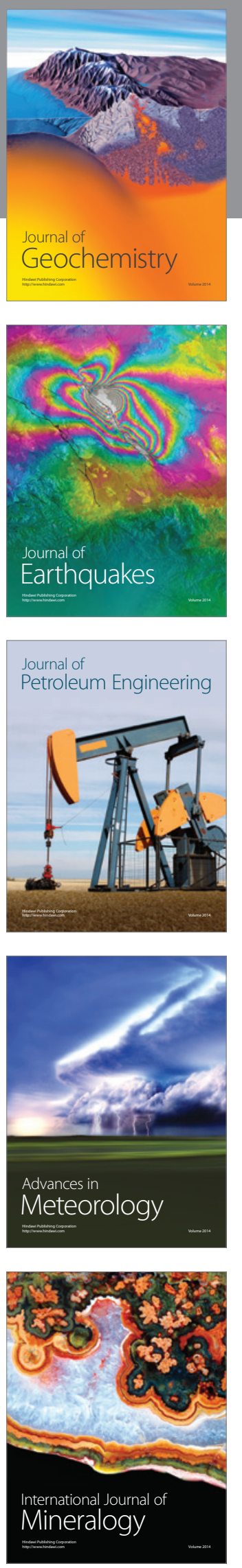
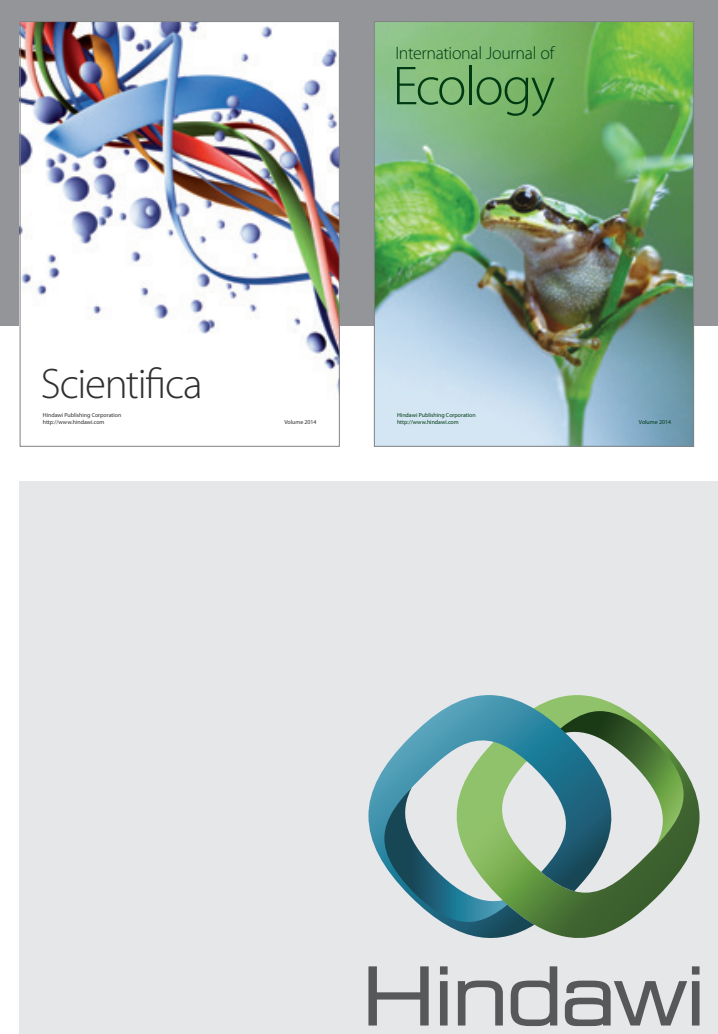

Submit your manuscripts at http://www.hindawi.com
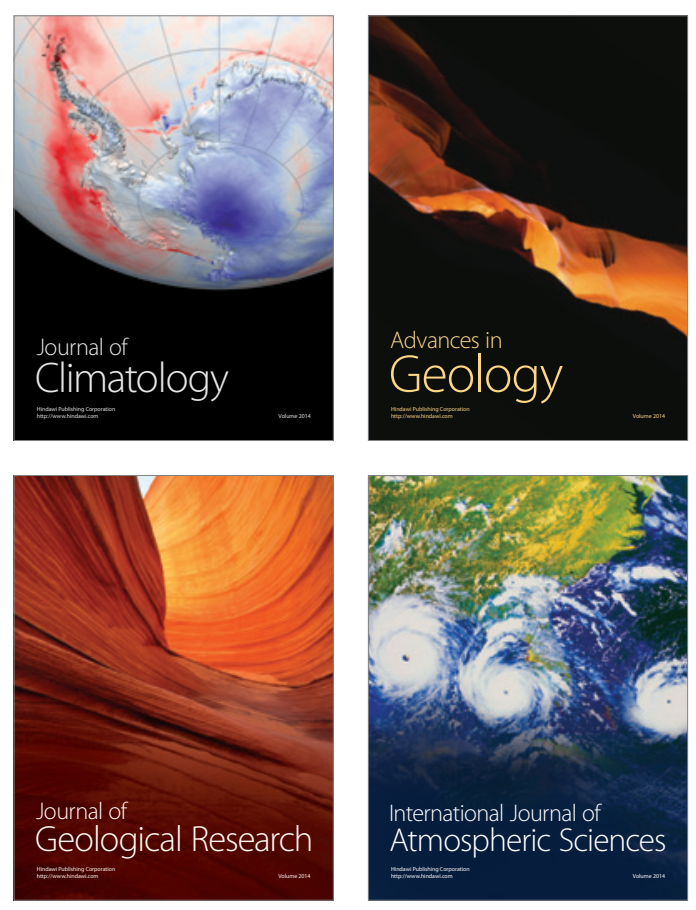
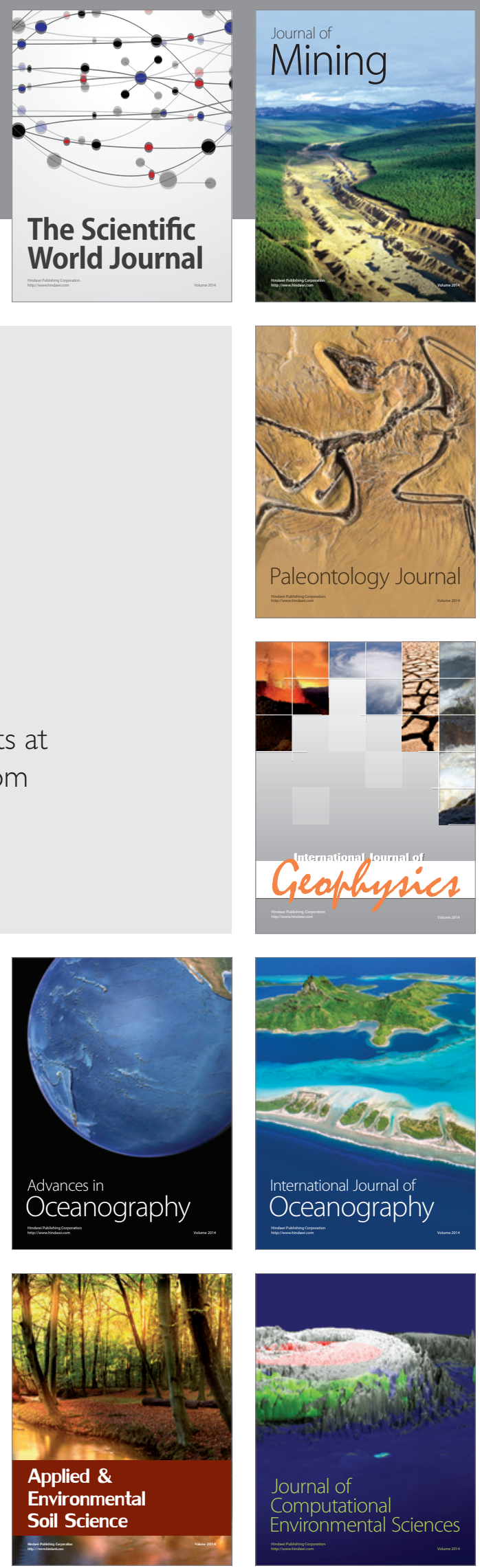